\title{
The Necessity of energy alternative under the haze background
}

\author{
Dan Ge ${ }^{1, a}$, Xingyu Liu ${ }^{1, b}$, Baiyu Gao ${ }^{3, c}$ and Tong Wang ${ }^{1, d}$ \\ ${ }^{1}$ State Grid Liaoning Electric Power Supply Co. Ltd, Shenyang, China

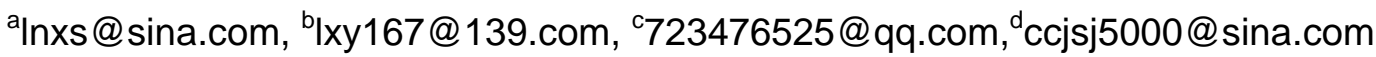

Keywords: Haze; Energy alternative; Low carbon

\begin{abstract}
The haze is more and more serious environmental pollution in the city, how to reduce haze and even achieve energy conservation is currently a serious problem, energy alternative is a very feasible option. The study puts forward an energy alternative plan from the macro-policy and industrial environment of Liaoning Province. We draw on the international mature experience and combine with the actual energy consumption of Liaoning, consider that surplus electricity currently exist in the field of energy consumption, consumption structure is highly rigid, $3 \mathrm{E}$ exist non-coordinated development, and urbanization accelerate pollution problems. In conclusion, the implementation of energy alternative is imperative.
\end{abstract}

\section{Introduction}

Since 2013, the average haze days in Liaoning Province reached a historical high. Compared with an average 17 haze days of recent 15 years, 20 days appeared in January which is rarely seen in history, and the wide range, long duration and extent of contamination are rare. Under the existing environmental capacity, air quality is inevitable declined, thus the emission reduction must be the only way to reduce air pollution. The replacement of industrial production, heating, cars and other industry which depend on coal, petroleum-based traditional energy by electricity is the most feasible and the most significant method. Energy scarcity, economic development and environment pollution is an inevitable and permanent task in the development of modern society. The low-carbon economy is the only path to coordinate between the three, and energy conservation is the fundament for social progress and continuity. Nowadays, the macro-policy, related industries actual, mature international experience or regional development status all point to a possible energy saving solutions -electrical energy alternative.

Meanwhile, the academic research on electrical energy alternative has been carried out, but the study is almost empty in Liaoning Province.

\section{The macro and industry background of electrical energy alternative in Liaoning}

From the macroeconomic policy background, "Twelfth Five-Year Plan" put forward to found safe, stable, economical and clean modern energy industry system. And adhere to build a resource-saving and environment-friendly society which accelerates the transformation of economic development as an important focal point. The country will take resource conservation and environmental protection as a basic national policy, save energy, reduce greenhouse gas emissions, develop recycling economy, promote low-carbon technologies, and take the road of sustainable development. In the 18th report of the party, the country put the construction of ecological civilization to a very prominent position, and format five integrated parallel development model of economic, political, cultural and social development. The country will promote energy production and consumption revolution, control the total energy consumption, strengthen energy conservation, and support the development of low-carbon energy industry and new energy, renewable energy to ensure national energy security $[1,2]$. The report first put forward environmental protection to a very important position, which is incorporated into the basic public services that environment protection is a fundamental responsibility of government. 
From the industrial background, China has become the superpower of the world's energy consumption, the sulfur dioxide, nitrogen oxides, soot emissions of coal combustion is huge which has become the most important reason of haze. August 15, 2013, National Grid put forward an electrical energy alternative embodiment, which require a comprehensive energy alternative in its operating area, and actively promote a new mode of the energy consumption: "substitution coal for electricity, substitution oil for electricity, electricity from the distance", and continuously improve the proportion of electricity in energy consumption.

\section{The analysis of energy consumption structure in Liaoning Province}

(1) Energy development generally favorable and energy consumption continually increasing

During the "Eleventh Five-Year", with the national strategy of revitalizing northeast old industrial base, and the stating of coastal economic belt, Shenyang Economic Zone, the province's energy supply and demand market is very active, the energy development go to a new level.

Table 1 Table of total energy consumption of national and part regions (million tons of standard

\begin{tabular}{|c|c|c|c|c|c|c|c|}
\hline \multicolumn{8}{|c|}{ coal) } \\
\hline Year & 2005 & 2006 & 2007 & 2008 & 2009 & 2010 & 2011 \\
\hline China & 2359.97 & 2586.76 & 2805.08 & 2914.48 & 3066.47 & 3249.39 & 3480.02 \\
\hline Liaoning & 136.11 & 149.87 & 165.44 & 178.01 & 191.12 & 209.47 & 227.12 \\
\hline Beijing & 55.22 & 59.04 & 62.85 & 63.27 & 65.70 & 69.54 & 69.95 \\
\hline Jilin & 53.15 & 59.08 & 65.57 & 72.21 & 76.98 & 82.97 & 91.03 \\
\hline Heilongjiang & 80.50 & 87.31 & 93.77 & 99.79 & 104.67 & 112.34 & 121.19 \\
\hline Shanghai & 82.25 & 88.76 & 96.70 & 102.07 & 103.67 & 112.01 & 112.70 \\
\hline Jiangsu & 171.67 & 190.41 & 209.48 & 222.32 & 237.09 & 257.74 & 275.89 \\
\hline Hunan & 97.09 & 105.81 & 116.29 & 123.55 & 133.31 & 148.80 & 161.61 \\
\hline Sichuan & 118.16 & 129.86 & 142.14 & 151.45 & 163.22 & 178.92 & 196.96 \\
\hline Shanxi & 55.71 & 61.29 & 67.75 & 74.17 & 80.44 & 88.82 & 97.61 \\
\hline
\end{tabular}

(2) Energy market supply and demand keep balance, power surplus is significant

The supply of energy markets in Liaoning are stable and the amount of coal from other provinces increases rapidly, the market supply and demand remains stable. In 2013, the production of province's state-owned coal mine was 46.57 million tons, with year-on-year growth of $2.1 \%$. The production of province's crude oil reached 78.8 million tons / year, the oil supply is sufficient.

In short, new capacity in Liaoning Province increases rapidly, wind energy and nuclear power as the representative of clean energy continues to combine to the grid, the supply is adequate, the surplus energy is obvious.

(3) The structure of energy consumption is highly rigid, coal take over the dominant position

From table 2, fossil fuels are still in a dominant position in Liaoning Province, and exhibit high rigidity.

Table 2 Coal, oil major consumption in 2009-2011 of Liaoning Province

\begin{tabular}{c|c|c|c|c|c|c}
\hline \multirow{2}{*}{ Project } & \multicolumn{3}{|c|}{ Coal (million ton) } & \multicolumn{3}{c}{ Oil (million ton) } \\
\cline { 2 - 7 } & 2009 & 2010 & 2011 & 2009 & 2010 & 2011 \\
\hline Total & 160.3252 & 169.0843 & 180.536 & 27.6611 & 38.1555 & 44.0343 \\
Thermal & 59.6053 & 66.5605 & 73.0528 & 0.1277 & 0.0891 & 0.107 \\
Heat & 22.5809 & 22.8855 & 24.1714 & 0.8467 & 0.7771 & 0.5044 \\
Industry & 32.7064 & 36.7335 & 37.6746 & 11.5728 & 16.0618 & 19.3509 \\
Traffic and mail & 0.9077 & 0.6703 & 0.6593 & 9.1362 & 10.4171 & 11.3358 \\
Living & 4.0024 & 3.7810 & 4.0672 & 0.6488 & 1.9116 & 2.3803 \\
\hline
\end{tabular}

Coal still occupies too large proportion in final energy consumption which directly led to increasingly serious environmental pollution. From Table 3, it can be further discovered that coal is still the main source of energy in Liaoning province's energy consumption, and the proportion is maintained at between 41.98 to $44.20 \%$, showing a very strong structural rigidity characteristics.

However, significant improvement in the power structure of Liaoning Province has been carried out. Hydropower accounts for 7\%, thermal power accounting for $76.34 \%$, wind power accounted for $14 \%$ and the proportion of nuclear power is 3\%. Proportion of thermal power by 2010 decreased from 
86.1\% down to $76.34 \%$ by 2011, wind power increased from $9.67 \%$ of 2010 to $14 \%$ of 2011, increased $4.33 \%$, power structure improved significantly.

Table 3 Energy consumption constitute of Liaoning province in 2006-2011 (million ton)

\begin{tabular}{l|c|c|c|c|c|c|c|c|c}
\hline & Coal & Coke & Oil & Petrol & Kerosene & Diesel & Fuel oil & Gas & Electricity \\
\hline 2006 & 127.10 & 17.07 & 79.26 & 5.79 & 0.51 & 8.56 & 3.30 & 1.74 & 49.62 \\
2007 & 138.37 & 19.60 & 84.09 & 6.46 & 0.56 & 9.62 & 3.20 & 1.89 & 54.92 \\
2008 & 147.12 & 22.99 & 84.83 & 6.04 & 0.37 & 11.34 & 5.42 & 2.16 & 57.04 \\
2009 & 153.47 & 24.41 & 83.80 & 6.83 & 0.30 & 11.81 & 4.28 & 2.19 & 60.12 \\
2010 & 160.33 & 27.95 & 93.58 & 8.73 & 0.34 & 14.04 & 5.09 & 2.53 & 69.29 \\
2011 & 180.54 & 33.86 & 95.67 & 10.40 & 0.40 & 16.09 & 5.59 & 5.20 & 75.22 \\
\hline
\end{tabular}

\section{Necessity Analysis of energy alternative strategy in Liaoning Province}

(1) Asymmetry of supply and demand power, capacity surplus is full

The total installed capacity of Liaoning Province showed a trend of increasing year by year, the installed capacity and power did not show the synchronization, and power generation capacity has not been fully realized.

Table 4 The power supply situation of Liaoning Province in 2001-2013

\begin{tabular}{c|c|c|c}
\hline & $\begin{array}{c}\text { Installed capacity } \\
\text { (million kwh) }\end{array}$ & $\begin{array}{c}\text { Power supply } \\
\text { (billion kwh) }\end{array}$ & $\begin{array}{c}\text { Power sale } \\
\text { (billion kwh) }\end{array}$ \\
\hline 2001 & 15.4038 & 68.361 & 65.132 \\
2004 & 16.5064 & 83.842 & 77.858 \\
2009 & 25.7680 & 119.400 & 116.721 \\
2011 & 34.0000 & 142.300 & 151.300 \\
2012 & 36.6331 & 141.466 & 154.781 \\
2013 & 39.6672 & 151.509 & 168.216 \\
\hline
\end{tabular}

Recent years, wind energy and solar energy in Liaoning Province existed the problem of "abandoning wind" and "abandoned light", which lead to equipment idle and cause serious waste of resources. Energy alternative will stimulate demand for electricity end-consumer areas, improve equipment efficiency, and can achieve energy conservation, environmental protection goal. From another perspective, with scientific and rationalization of macro-control, green GDP will replace the traditional GDP to measure the level of economic development, so the traditional GDP growth slowed down to a certain extent, which will directly lead to a reduction of total energy consumption, and thus there will be some decline in social consumption. Under established capacity, the gap between electricity supply and demand will further widen, the surplus energy will be further highlighted.

(2) Non-coordinated development of Energy, Environment and Economy (3E), low-carbon economy is imperative

The Energy-Economy-Environment (3E) of Liaoning even China conflict to each other in the development process, while environmental capacity and other environmental factors on the development of energy produced significant regulatory role, and bring economic development a high cost. In addition, the economic development and energy production and consumption also reflect a certain degree of non-equilibrium [3]. Therefore, building an ecological civilization Liaoning, development of low-carbon economy is the core content of transformation of economic development. One breakthrough is the implementation of "energy alternative" strategy.

(3) The energy efficiency is low, and energy consumption needs innovation

Currently, the energy consumption structure is irrational of Liaoning Province, which is still coal and crude oil, environmental pollution is serious, energy consumption per unit of GDP is much higher than the national average, the energy efficiency is low. Recent years, coal of power generation accounted for the proportion of the total coal consumption is about $41 \%$, significantly lower than the national average of 55\%, well below the proportion of Europe and the United States; the proportion of coal in Liaoning Province in the final energy consumption up to 83\%, far higher than the national average of 48 percent, electricity accounts for less than $10 \%$ (the national average is $20 \%, 40 \%$ or 
more in developed countries). Inefficient use of coal has increased the total energy consumption, but also increases the pollution of the environment.

(4) Urbanization accelerated environmental pollution, and energy saving bear huge pressure

On the one hand, the rapid progress of urbanization will take population into city and bring environmental pollution [4]. According to the calendar year, "Liaoning Statistical Yearbook", the total amount of waste water discharged from Liaoning Province of 1.89218 billion tons in 2002 to 2011 of 2,322,470,200 tons, an increase of 430,290,200 tons a decade, an increase of 18.53\%. The sewage treatment rate of 50\% in 2009 increased to $74.93 \%$ in 2010, urban sewage treatment rate in Liaoning Province is below the national average of 7.38 percentage points. In the United States and Japan and other developed countries, the sewage treatment rate is $100 \%$, compared to the Liaoning Province there is still much room for improvement, but the sewage treatment needs strong and reliable supply of electricity.

On the other hand, large-scale urbanization and infrastructure seriously affect the ecological environment. Infrastructure will lead to a lot of soot and sulfur dioxide, carbon dioxide and other gases polluting and the greenhouse effect [5,6]. According to statistics, the total building energy consumption accounted $30 \%$ of total energy consumption, emissions for $25 \%$ of the total community emissions. And in northern Liaoning province, nearly half of the heating season each year, the coal of every year for heating accounted for $3 / 5$ of the province's total coal consumption.

\section{Summary}

At present, research on energy alternative is relatively little, this study taken haze as a starting point to solve the current problem of energy conservation by "electrical energy alternative". The energy consumption structure of Liaoning Province is unreasonable, the dominant position of coal is much rigid, and Liaoning Province has a very large potential for power production, the energy is significantly surplus. On the other side, the development of economic, energy, and environment and rapid advance of urbanization must propose specific energy saving measures, and "electrical energy alternative" is a very workable solution.

Next, the study will focus on the feasibility analysis of "energy alternative" implementation of Liaoning Province, including the design and supply systems of market mechanisms, the specific rehabilitation programs and implementation methods of winter heating, transportation, industrial boilers and so on. Further study of these issues will help "electrical energy alternative" smooth implementation and realization of energy saving.

\section{References}

[1] Y. Xiong. Road and operation of new energy Talents in China. China Electric Power Education.21:38-41 (2013)

[2] Z. Zeng. Study on Chinese Ecological Civilization Construction from the Economic Perspective. Journal of Finance and Economics Theory.01:34-38(2013)

[3] D. Wang. Based on China's energy industry development model 3E Coordinated Development. North China Electric Power University. ( 2012)

[4] Z.J. Li, S.H. Sheng. Urbanization Environmental Protection: Worry and coping. Journal of Chinese Academy of Governance.04:69-73(2012).

[5] D .L. Cao, Y. Yuan, Z. X. Li. Application and Efficiency Evaluation of Alternative Energy. Power System and Clean Energy.04:30-34 (2011)

[6] S. H. Song, C. H. Liu, Z. B. Li, et al. Implementation of alternative energy to promote energy conservation. Technological Pioneers.21:72 (2013) 